\title{
Beyond agroecology: Making sustainable agriculture part of a political agenda
}

\author{
Miguel A. Altieri
}

Although interest in sustainable agriculture has emerged worldwide, the motivation to pursue sustainable agricultural development varies according to the political, ecological, and socioeconomic climate of each region. In the industrialized countries (ICs) a major factor has been the need to deal with the consequences of technology-induced environmental degradation resulting from a sort of "development oversaturation." Conversely, in developing countries (LDCs), "development" has historically not reached a vast population of resource-poor farmers. Therefore, a driving force has been the need to match agricultural development with the needs of the rural poor.

In both cases, a central idea has been the development of an "appropriate technology" capable of translating productive potentials into sustainable livelihoods for all. Several agricultural research and development schemes have been suggested to reach this goal, among them agroecology.

In its various conceptions, agroecology has been proposed as a new scientific discipline that defines, classifies, and studies agricultural systems from an ecological and socioeconomic perspective. In addition to providing a methodology to diagnose the "health" of agricultural systems, agroecology is expected to delineate the ecological principles necessary to develop sustainable production systems.

Agroecology in the United States and the industrialized countries. In the 1980's several U.S., European, and Canadian universities and agricultural research centers have initiated research and education activities aimed at the development of land restorative, environmentally sound, economically viable, and socially acceptable agricultural systems. At the core of these projects is the desire to develop agricultural systems that sustain production in the long term without degrading the resource base. Thus the arsenal of options that potentially meet these goals includes a variety of low-input technologies that improve soil fertility and conservation, maximize recycling, enhance biological pest control, and diversify production. Intrinsic to these projects is the conviction that, as long as the proposed systems benefit the environment and are profitable,

Miguel A. Altieri is Associate Professor, Division of Biological Control, University of California-Berkeley, Albany, CA 94706. sustainability will eventually be achieved and all people will benefit. Thus, sustainable agriculture technologies are seen as relatively neutral. Therefore, the question of which segments of society benefit from this technology is of little concern since it is assumed that what is good for the environment is good for society at large. Such a position can prove problematic and dangerous for four main reasons:

a) If capital relations of production are not taken into account as a determinant of how and to whom technology is delivered, technology (whether sustainable or not) will continue to be delivered preferentially to the class holding the capital and political power.

b) The focus on low-input technologies as a main component of sustainable agricultural development will cause several biotechnologies that clearly are not scale-neutral or capital-neutral to be proposed as viable options, thereby enhancing farmers' dependence on the private sector.

c) If the issue of economics of scale is not addressed, and if it is argued that sustainable production methods should not be restricted to small farmers, corporate and large-scale farmers will rapidly shift to alternative methods because there is a good prospect for monetary gain (i.e., low inputs reduce costs of production). This shift potentially will displace some small farmers committed to sustainable agriculture not only because of financial reasons, but because of ecological and moral ones. As competition increases, more small farmers will shift to specialty crops oriented to elite markets as a way to exploit economic windows in order to survive in the capitalist-oriented economy. Such trends are already occurring in California.

d) If only environmental quality is emphasized, and if the fact that large-scale farmers are at least not "polluting" any more is considered sufficient, other factors that make a sustainable agriculture socially just and humane can be overshadowed. Within this framework, the fact that certain organic farmers do not provide proper wages and living conditions to their farm workers can easily be "overlooked." This is undesirable and obviously can complicate and even polarize the labor issues within the organic industry, as in the grape boycott led by the United Farm Workers' Union.

It, therefore, is crucial that scientists involved in the search
American Journal of Alternative Agriculture 
for sustainable agricultural technologies be concerned about who will ultimately benefit from them. This requires them to recognize that political determinants enter when basic scientific questions are asked, and not only when technologies are delivered to society. Thus what is produced, how it is produced, and for whom it is produced are key questions that need to be addressed if a socially equitable agriculture is to emerge. When such questions are examined, issues of land tenure, labor, appropriate technology, public health, and research policy unavoidably arise. Examination of these questions should proceed even if it means recognizing that political systems other than the capitalist model might represent the best hope to assault the structural basis underlying the environmental crisis of modern agriculture.

Agroecology in the developing countries. In the LDCs, history shows that increases in agricultural productivity, whether through sustainable technologies or not, cannot solve the problem of rural poverty. Thus a major dilemma facing agroecologists in LDCs is how to further increase agricultural productivity in a way that allows the rural poor to benefit significantly. The challenge, however, is to realize that this is not really possible without improving the access of peasants to land, water, other natural resources, as well as to equitable credit, markets, and appropriate technologies. Only political change derived from progressive government or strong community-based actions can secure farmers' control over the institutions that govern access to resources and inputs. Agroecology can only hope to provide the ecological basis to manage the resources once available to the rural poor. In other words, as an agricultural development approach, agroecology cannot confront the structural and economic factors that underlie rural poverty. As emphasized above, this will require a much broader development approach that, among other things, effectively addresses the question of social organization of the peasantry.

Therefore, more than creating or transferring new technology, a fundamental idea of agroecology should be to encourage the emergence of an attitude towards the technological process that allows farmers to discriminate, select, and adopt new technologies, and also to validate those that originate within their own social group. In Latin America several non-government organizations have taken this approach, creating programs that emphasize research, education, technical assistance, and credit provision aimed at the development of peasant agriculture. Many of these groups have demonstrated a special ability to understand the specific and differentiated nature of small-farm production and have promoted some successful experiences in generation and transfer of peasant technology.

These groups recognize, however, that ultimate sustainability will be reached as farmers increase their access to land, resources, and a suitable technology that allows them to ecologically manage these resources and also become socially organized to secure governance of resources, equity of access to markets for inputs and products, and to income derived from harvests.

Conclusions. Regardless of whether the worldwide problem of sustainability of agriculture gets addressed through a political agenda aimed at modifying governance of and access to resources, the question of technology development will remain a vital one. In this context, agroecology can be a useful tool to guide such a process.

Undoubtedly, agroecology has allowed us to better understand in an integrated manner the various factors that govern agricultural productivity and to develop new technological avenues to overcome these factors in a more environmentally sound manner. However, by perceiving the problem of sustainability solely as a problem of sustaining production without degrading the resource base, most agroecological approaches are restricted in their ability to understand and address the root causes that drive agricultural systems to become nonsustainable. Clearly, new sustainable agroecosystems cannot be implemented without modifying the socioeconomic determinants that govern what is produced, how it is produced, and for whom it is produced. The technological issues addressed by agroecology must assume their corresponding role within a political agenda that incorporates social and economic dimensions in its development strategy. Only policies and actions derived from the implementation of such strategy can confront the structural and economic factors that underlie the agricultural-environmental crisis in the ICs and rural poverty in the LDCs.

Agroecologists must continue their multidisciplinary research and training efforts so that our understanding of the complex factors governing agricultural sustainability expands. But this scientific understanding must be guided by a broader understanding: that of the relationship between political institutions, social classes, and the scientific community. Continuation of a purely technological focus, even if the promoted technologies are "sustainable," will further obscure the recognition of the factors that make agriculture unsustainable in the first place.
Guidelines for Developing University Sustainable Agriculture Programs, from the Wisconsin Rural Development Center (WRDC), identifies central characteristics of successful programs. It is designed both to guide university groups and to provide interested citizens with a tool to judge such programs. Copies of the 32-page guide are $\$ 5$ from the WRDC, P.O. Box 504, Black Earth, WI 53515-0504. 